УДК 371.133 .2

DOI $10.21661 / \mathrm{r}-466633$

\title{
Е.А. Маслова
}

\section{ФАСИЛИТАТИВНАЯ НАПРАВЛЕННОСТЬ УЧИТЕЛЯ КАК УСЛОВИЕ ОРГАНИЗАЦИИ ГРУППОВОЙ РАБОТЫ С МЛАДШИМИ ШКОЛЬНИКАМИ}

Аннотация: в статье рассматриваются вопросы организации групповой работы младших школьников, ее цель, задачи, преимущества и трудности, возникающие при ее подготовке. Автор раскрывает сущность и значение педагогической фасилитации, обращяает внимание на то, что одним из условий ее эффективной организации будет фасилитативная направленности учителя и безопасная образовательная среда. Фасилитативная направленность рассматривается через компоненты: эмоционально-когнитивный, праксеологически-поведенческий, рефлексивный компоненты.

Ключевые слова: групповая работа, сотрудничество, педагогическая фасилитаџия, безопасная образовательная среда, педагогическая фасилитаџия, фасилитативная направленность учителя.

\section{E.A. Maslova}

\section{THE FACILITATIVE ORIENTATION OF THE TEACHER AS A BASE CONDITION FOR THE ORGANIZATION OF GROUP WORK WITH THE ELEMENTARY SCHOOL STUDENTS}

Abstract: the questions connected with the organization of group work with the elementary school students are revised in this article as well as its object, objectives, advantages and difficulties which may occur during the preparation work. The author reveals the essence and meaning of the pedagogical facilitation and draws attention that one of the conditions for its effective organization is the pedagogical facilitation of the teacher and the safe educational environment. The pedagogical facilitation is being reviewed though the following components: emotionally-cognitive, praxeologically-behavioural, reflexive ones. 
Keywords: group work, cooperation, pedagogical facilitation, safe educational process, pedagogical facilitation, facilitative orientation of a teacher.

ФГОС НОО предполагает обеспечение потребностей детей в общении и совместной работе через объединение индивидуальных, групповых и фронтальных видов работ. Групповая работа- одна из самых продуктивных форм организации учебного сотрудничества детей, которая предполагает, что процесс обучения происходит в совместной деятельности.

Ю.К. Бабанский, М.Д. Виноградова, В.К Дьяченко, Е.Д. Маргулис, М.Н. Скаткин, Г.А. Цукерман и др. рассматривали некоторые аспекты организации групповой работы. Вопросами содержания, организации совместной работы, определением структуры и состава учебных групп, взаимодействием участников совместной учебной работы за рубежом занимались Д. Брунер, М. Шерид, Я. Вартецкий, Е. Рауш, Е. Фурман, 3. Фабиан, Ц. Искарова и др.

В условиях групповой работы важнейшее значение приобретает проблема общения ее участников. В своих исследованиях к ней обращались многие психологи А.А. Бодалев, В.Л. Кричевский, К.А. Абульханова-Славская, Г.М. Андреева, А.И. Донцова, А.В. Петровский и др. Р.Я. Гузман, Г.Г. Кравцов, Е.Д. Маргулис, А.Н. Маркова, В.В. Рубцов и др. раскрыли влияние групповой деятельности на формирование коллективных взаимоотношений школьников, мотивацию и производительность их познавательной деятельности.

Л.С. Выготский считал сотрудничество, взаимопомощь, подражание необходимыми факторами учебного процесса. Благодаря сотрудничеству учащийся приобретает уверенность в своих знаниях, умениях, проявляет большую сообразительность, смекалку, чем в самостоятельной работе. Исследования показывают, что такое сотрудничество не должно ограничиваться лишь взаимодействием ученика с учителем, оно обязательно должно предполагать и сотрудничество со сверстником (В.В. Давыдов, Г.А. Цукерман, Т.А. Матис, А.К. Маркова и др.) [2]. Так, Г.А. Цукерман, ссылаясь на исследования, посвященные роли сверстников в психическом развитии ребенка, утверждает, что «между новым действием, выполняемым лишь с помощью взрослого, и самостоятельным 
действием ребенка есть область полусамостоятельности [7]. Можно согласиться с М.И. Витковской, что помощь взрослого не только не нужна, но порой и вредна: на его «полюс» немедленно «перетекает» рефлексивная часть работы (целеполагание, контроль, оценка и др.). В области полусамостоятельности ребенку помогает сверстник» [1] Отсюда следует необходимость сотрудничества со сверстником для успешного формирования учебной деятельности младшего школьника.

Рассмотрим сущность групповой работы и влияние фасилитативной направленности учителя при ее организации.

И.Б. Первин, М.Д. Виноградова определяют цель групповой работы как активное включение каждого ученика в процесс усвоения учебного материала.

Задачи групповой работы:

1. Активизация познавательной деятельности.

2. Развитие навыков самостоятельной учебной деятельности: определение ведущих и промежуточных задач, выбор оптимального пути, умение предусматривать последствия своего выбора, объективно оценивать его.

3. Развитие умений успешного общения (умение слушать и слышать друг друга, выстраивать диалог, задавать вопросы на понимание и т. д.).

4. Совершенствование межличностных отношений в классе.

Преимущества групповой формы работы:

1. Повышение интереса к учению, выработка положительного отношения к нему, и, как следствие этого, улучшение результативности учебного процесса.

2. Развитие навыков самостоятельной учебной деятельности.

3. Групповая работа развивает коммуникативные навыки, которые требуются для успешного контакта с другими людьми.

4. Работа в группах открывает широчайшие возможности для выработки навыков социальной перцепции (восприятие других людей, их внешности, речи, жестов, мимики, оценка их действий и поступков), которая способствует совершенствованию межличностных отношений в классе. 
Несомненно, групповая форма организации работы имеет немало достоинств. Однако при ее организации можно выделить определенные сложности:

1. Групповой работе надо сначала научить. Для этого учитель должен потратить время на каких-то уроках. Без соблюдения этого условия групповая работа бывает неэффективна.

2. Организация групповой работы требует от учителя особых умений, затрат усилий.

3. При непродуманном комплектовании групп некоторые ученики могут пользоваться результатами труда более сильных одноклассников.

4. Разделение на группы может проходить непросто, даже драматично.

5. В классе всегда найдутся дети, желающие работать в одиночестве. Им надо создать условия для этого. Это дополнительные сложности для учителя [3].

Таким образом, эффективность групповой работы с младшими школьниками во многом зависит от установок, направленности личности учителя. На наш взгляд одним из условий успешной организации групповой деятельности является установка учителя на педагогическую фасилитацию.

В науке выделяют фасилитацию социальную и педагогическую. Под первой понимают повышение скорости или продуктивности деятельности личности вследствие актуализации в ее сознании образа другого человека (или группы людей). Появление термина «фасилитация» связано со статьей Роберта Зайонца «Социальная фасилитация», опубликованной в американском журнале «Science». Явление «фасилитации» было зафиксировано в опытах французского физиолога К.Фере, изучавшего психогальванический рефлекс. В широком социальном смысле фасилитация предполагает стимулирующее влияние одних людей на поведение, деятельность и общение других. Учеными было замечено, что в присутствии фасилитатора человек действует более раскованно, активно при положительном отношении людей друг к другу.

Понятия «фасилитация» и «фасилитатор» (от англ. facilitate - облегчать, помогать, способствовать) пришли в педагогику из гуманистической психологии и связаны с работами К.Роджерса. Разработку концепции педагогической 
фасилитации начал в 50-х гг. 20 века К. Роджерс совместно с другими представителями гуманистической психологии. К. Роджерс рассматривал фасилитацию учения как «процесс, посредством которого мы можем и сами научиться жить, и способствовать развитию учащегося» [5] Ученый считал, что реформирование образования должно основываться на изменении личностных установок учителя (в том числе, и направленности), осуществляющихся в процессе его межличностного взаимодействия с учащимися.

В отечественной психологии проблемой фасилитации занимаются Э.Ф. Зеер, И.В. Жижина, Р.В. Овчарова, О.Н. Шахматова и др. Изучая этот феномен, авторы устанавливают его особенности и психотехнологии развития. Работы Е.Ю. Борисенко, Е.Г. Врублевской, О.И. Димовой, Р.С. Димухаметова, Л.Н. Куликовой, А.А. Майера, С.Я. Ромашиной, А.М. Рябкова, Л.И. Тимониной и др. посвящены педагогическому аспекту проблемы фасилитации. Е.Ю. Борисенко раскрывает вопросы внедрения форм и методов работы по фасилитации, развития экзистенциональной направленности школьников. Готовность учителя к фасилитирующему общению средствами иностранного языка рассмотрена в работах О.В. Козиной, которое определяется развитием коммуникативных умений (речевых, саморегуляции, гностических, конструктивных) с ориентацией на личность обучаемых. Развитие слабоуспевающих учеников через социально-педагогическую фасилитацию рассматривала Л. И. Тимонина. В исследованиях Е.Г. Врублевской, О.И. Димовой изучается фалиситирующее общение как вид педагогического взаимодействия Р.С. Димухаметовым разработана концепция фасилитации, создающая теоретический фундамент для системы повышения квалификации.С.Я. Ромашина и А.А. Майер рассматривают фасилитацию развития субъектов дошкольного образования.

Э.Ф. Зеер под педагогической фасилитацией понимает - усиление продуктивности образования (обучения, воспитания) и развитие субъектов профессионально-педагогического процесса за счет особого стиля общения и личности педагога.В таком определении педагогической фасилитации автор указывает на 
значимость качеств личности педагога, способствующих возникновению и проявлению данного феномена.

Несколько по-другому понимает педагогическую фасилитацию О.Н. Шахматова, которая, рассматривая особенности педагогической фасилитации, раскрывает ее через «усиление продуктивности образования (обучения, воспитания) и развития субъектов педагогического процесса за счет особого стиля межличностного взаимодействия и качеств личности педагога». В отличие от определения Э.Ф. Зеера, данное определение несколько уже рассматривает «сферу» влияния фасилитации, так как автор говорит о ее роли в педагогическом взаимодействии, которое является компонентом педагогического общения (А.Н. Леонтьев, Ф.М. Ломов и др.). Фасилитация также рассматривается О.Н. Шахматовой как процесс и профессиональное новообразование личности педагога, интегрирующее индивидуально-психологические особенности когнитивной, эмоциональной и поведенческих сфер.

Выводы, сделанные О.Н. Шахматовой А.А. Майером и С.Я. Ромашиной, позволили в основу понимания структуры и содержания фасилитации положить основной принцип гуманистической психологии и терапии «понять-принятьпростить», который связали с объектами воздействия педагога и соответствующими структурами его личности (направленность, компетентность, профессионально- важные и значимые личностные качества). Отсюда вытекает очевидная связь фасилитации с социально-психологическими качествами личности, способствующими межличностному и ролевому взаимодействию с воспитанниками, и, содействующими ребенку в определении и совершенствовании его отношения к себе, другим людям и окружающему миру. Следовательно, сущность фасилитации в образовании, в глобальном значении, заключается в создании условий для самореализации субъектов образования в ведущей деятельности (младший школьник- учебная, подросток- межличностное общение, студентучебно-профессиональная, учитель- профессиональная) и в познании мира и себя в этом мире. 
Фасилитирование - это облегчение группового процесса, а основная задача фасилитатора в учебной группе, в классе- это стимулирование и инициирование осмысленного учения. А.А. Майер, А.В. Межина и С.Я. Ромашина, с которыми согласимся в том, что «фасилитация в глубоком смысле означает раскрытие настоящих человеческих качеств у присутствующих участников группы и помощь им стать больше, чем просто участники». Следовательно, наличие установки на фасилитацию, направленность на нее у педагогов способствует самоактуализации всех субъектов учебно-воспитательного процесса.

Согласно К. Роджерсу, основными установками, которыми должен обладать педагог-фасилитатор, являются:

- «открытость» педагога собственным мыслям, чувствам, переживаниям, а также способность открыто выражать и транслировать собственные мысли и переживания в межличностном общении с учащимися;

- «принятие» и «доверие», выражающее внутреннюю уверенность педагога в возможностях и способностях каждого учащегося;

- «эмпатическое понимание», выражающееся в видении педагогом поведения учащегося, оценки его реакций, действий, поступков с точки зрения учащегося; оно позволяет педагогу взглянуть на все вокруг и на себя глазами детей [5]. Действия, характерные для педагога-фасилитатора, выделены в исследованиях О.В. Козиной:

- умение заинтересовать при объяснении и подаче учебного материала с целью эффективного принятия и усвоения его детьми (умение мотивировать);

- слышать и понимать ребенка, чувствовать его настроение, испытываемые трудности (умение проявлять толерантность, эмпатию);

- поощрять, создавать ситуацию «лестницы успеха», обеспечивать чувство полноценности, стремление к преодолению трудностей в педагогическом процессе и в жизни (умение фасилитировать).

Исходя из, определения педагогической направленности Л.М. Митиной, определения педагогической фасилитации Э.Ф.Зеера, под фасилитативной направленностью личности будем понимать положительное отношение к 
ребенку, к себе и деятельности, выражающееся в создании условий для продуктивного образования и безопасного развития всех субъектов образовательного процесса за счет личностно-ориентированного стиля общения и деятельности.

Структуру фасилитативной направленности будут составлять компоненты: эмоционально-когнитивный (предполагает осознание и принятие системы ценностей), праксеологически- поведенческий (предполагает овладение фасилитативной технологией и развитие навыков безопасного поведения по реализации ценностей педагогической деятельности, лежащих в ее основе), рефлексивный (предполагает самоанализ и самооценку собственной деятельности и поведения, а также деятельности и поведения ребенка).

На основе анализа литературы по проблеме можно выделить и соотнести 3 группы требований к организации групповой работы с младшими школьниками, обеспечивающих ее эффективность, и компоненты фасилитативной направленности учителя:

1. Требования к личности учителя-направленность на себя.

2. Требования к организации совместной деятельности - направленность на деятельность.

3. Требования по организации общения учащихся - направленность на ребенка.

Наполним содержанием данные требования, исходя из структуры фасилитативной направленности личности учителя.

Фасилитативная направленность учителя при организации

групповой работы

\begin{tabular}{|c|c|c|}
\hline Направленность на себя: & $\begin{array}{c}\text { Направленность на } \\
\text { педагогическую деятельность }\end{array}$ & $\begin{array}{c}\text { Направленность } \\
\text { на ребенка }\end{array}$ \\
\hline \multicolumn{3}{|c|}{ Эмоционально-когнитивный компонент фасилитативной направленности } \\
\hline $\begin{array}{l}\text { 1. Физическое «Я» педа- } \\
\text { гога: } \\
\text { направленность на осо- } \\
\text { знание и принятие себя } \\
\text { на физическом уровне } \\
\text { (своего тела, состояния }\end{array}$ & $\begin{array}{l}\text { 1. Мотивационно-целевой компо- } \\
\text { нент педагогической деятельности: } \\
\text { направленность на осознание и при- } \\
\text { нятие цели групповой работы. } \\
\text { 2. Коммуникативный компонент пе- } \\
\text { дагогической деятельности: }\end{array}$ & $\begin{array}{l}\text { 1. Физическое «Я» ре- } \\
\text { бенка: } \\
\text { направленность на созна- } \\
\text { ние и принятие физиче- } \\
\text { ского «Я» ребенка, его }\end{array}$ \\
\hline
\end{tabular}

8 https://interactive-plus.ru

Содержимое доступно по лицензии Creative Commons Attribution 4.0 license (CC-BY 4.0) 


\begin{tabular}{|l|l|}
\hline здоровья, проблем и & направленность на осознание и при- \\
причин заболеваний), и & нятие педагогического общения (фа- \\
сознание тех изменений, & силитативного общения) как дея- \\
которые необходимы, & тельности и условия организации \\
при организации груп- & групповой работы. \\
повой работы. & 3. Праксеологический компонент \\
2. Личностное «Я» педа- & педагогической деятельности: \\
гога: & направленность на осознание и при- \\
направленность на осо- & нятие способов организации без- \\
знание и принятие своей & опасного образовательного процесса \\
личности, образа «Я», & и среды в ходе организации группо- \\
своих особенностей, не- & вой работы. \\
обходимых при органи- & 4. Рефлексивный компонент педаго- \\
зации групповой ра- & гической деятельности: \\
боты. & направленность на осознание и при- \\
3. Социальное «Я» педа- & нятие самоанализа и самооценки пе- \\
гога: & дагогом своей работы и содержа- \\
направленность на осо- & тельной оценки деятельности ре- \\
знание и принятие себя & бенка в ходе организации групповой \\
как субъекта групповой & работы. \\
работы. &
\end{tabular}

индивидуальных особенностей.

2. Личностное «Я» pe-

бенка:

направленность на осо-

знание и принятие лич-

ности ребенка, его инте-

ресов и потребностей

при организации группо-

вой работы.

3. Социальное «Я» ре-

бенка:

Направленность на осо-

знание и принятие педа-

гогом ребенка как субъ-

екта групповой работы.

Праксеологически-поведенческий компонент фасилитативной направленности

1.Физическое «Я» педагога:

направленность на овладение и применение способов укрепления своего здоровья, которые необходимы, при организации групповой работы.

2. Личностное «Я» педагога:

направленность на овладение способами самопознания и их применение в ходе организации групповой работы.

3. Социальное «Я» педагога:

направленность на овладение способами взаимоотношений и взаимодействия с обучающимися в ходе организации групповой работы
1. Мотивационно-целевой компонент педагогической деятельности: направленность на овладение способами постановки цели групповой работы.

2. Коммуникативный компонент педагогической деятельности: направленность на овладение способами фасилитативного общения (взаимодействия) и реализация их в ходе организации групповой работы.

3. Праксеологический компонент педагогической деятельности: направленность на овладение и применение способов организации безопасного образовательного процесса и среды в ходе организации групповой работы.

4. Рефлексивный компонент педагогической деятельности:

направленность на овладение и применение способов самоанализа, самооценки педагогом своей работы и содержательной оценки деятельности ребенка в ходе организации групповой работы.
1. Физическое «Я» pe-

бенка:

направленность на овладение и применение способов сохранения и укрепления здоровья ребенка; создание безопасной образовательной среды в ходе организации групповой работы. 2. Личностное «Я» ребенка: направленность на овладение действиями по принятию ребенка, его интересов и потребностей в ходе организации групповой работы..

3. Социальное «Я» peбенка: направленность на овладение способами организации «пространства детства» и взаимодействия ребенка с социальной средой в ходе организации групповой работы. 


\begin{tabular}{|c|c|c|}
\hline $\begin{array}{l}\text { 1. Физическое «Я» педа- } \\
\text { гога: } \\
\text { направленность на само- } \\
\text { анализ и самооценку } \\
\text { своего физического со- } \\
\text { стояния и произошед- } \\
\text { ших изменений в ходе } \\
\text { организации групповой } \\
\text { работы. } \\
\text { 2. Личностное «Я» педа- } \\
\text { гога: } \\
\text { направленность на само- } \\
\text { анализ и самооценку } \\
\text { личностных изменений } \\
\text { в ходе организации } \\
\text { групповой работы. } \\
\text { 3. Социальное «Я» педа- } \\
\text { гога: } \\
\text { направленность на само- } \\
\text { анализ и самооценку } \\
\text { себя как субъекта груп- } \\
\text { повой работы. }\end{array}$ & $\begin{array}{l}\text { 1. Мотивационно-целевой компо- } \\
\text { нент педагогической деятельности: } \\
\text { направленность на самоанализ и са- } \\
\text { мооценку по постановке целей груп- } \\
\text { повой работы. } \\
\text { 2. Коммуникативный компонент пе- } \\
\text { дагогической деятельности: } \\
\text { направленность на самоанализ и са- } \\
\text { мооценку результатов фасилитатив- } \\
\text { ного общения (взаимодействия) в } \\
\text { ходе организации групповой ра- } \\
\text { боты. } \\
3 . \text { Праксеологический компонент } \\
\text { педагогической деятельности: } \\
\text { направленность на самоанализ и са- } \\
\text { мооценку деятельности по организа- } \\
\text { ции безопасного образовательного } \\
\text { процесса и среды в ходе организа- } \\
\text { ции групповой работы. } \\
4 . \text { Рефлексивный компонент педаго- } \\
\text { гической деятельности: } \\
\text { направленность на самооценку, са- } \\
\text { моанализ и содержательную оценку } \\
\text { субъектов безопасного образова- } \\
\text { тельного процесса и среды в ходе } \\
\text { организации групповой работы. }\end{array}$ & $\begin{array}{l}\text { 1. Физическое «Я» ре- } \\
\text { бенка: } \\
\text { направленность на само- } \\
\text { анализ и самооценку дея- } \\
\text { тельности на укрепление } \\
\text { физического здоровья и } \\
\text { создания безопасной об- } \\
\text { разовательной среды в } \\
\text { ходе организации груп- } \\
\text { повой работы. } \\
\text { 2. Личностное «Я» ре- } \\
\text { бенка: } \\
\text { направленность на само- } \\
\text { анализ и самооценку дея- } \\
\text { тельности (действий) по } \\
\text { принятию ребенка в ходе } \\
\text { организации групповой } \\
\text { работы. } \\
3 . \text { Социальное «Я» ре- } \\
\text { бенка: } \\
\text { направленность на само- } \\
\text { анализ и самооценку дей- } \\
\text { ствий по организации } \\
\text { «пространства детства» и } \\
\text { взаимодействия ребенка } \\
\text { с социальной средой в } \\
\text { ходе организации груп- } \\
\text { повой работы. } \\
\end{array}$ \\
\hline
\end{tabular}

Таким образом, организация групповой работы в учебной деятельности младших школьников является сегодня одной из важнейших задач, которую должен решить учитель. Фасилитативная направленность учителя будет способствовать эффективному управлению групповой работой младших школьников, через личностные качества педагога и установки на безопасную совместную деятельность.

\section{Список литературы}

1. Витковская М.И. Обучение младших школьников в совместной деятельности / М.И. Витковская. - Псков: ПГПИ имени С.М. Кирова, 2000. - 96 с.

2. Выготский Л.С. Избранные психологические исследования / Л.С. Выготский. Т. 1. - М.: Педагогика, 1956. - 479 с.

3. Глазкова А. Организация индивидуальной, групповой, коллективной деятельности / А.И. Глазкова // Начальная школа,1999. - №10. - С. 43-49. 
4. Лийметс Х.И. Групповая работа на уроке / Х.И. Лийметес. - М.: Наука, 1975. $-62 \mathrm{c}$.

5. Роджерс К. Свобода учиться / К. Роджерс. - М.: Смысл, 2002. - 527 с.

6. Ромашина С.Я. Фасилитация развития субъекта образования: Учебно-методическое пособие / С.Я. Ромашина, А.А. Майер. - М.: МГПУ, 2010. - 63 с.

7. Цукерман Г.А. Обучение учебному сотрудничеству / Г.А. Цукерман, Н.А. Елизарова [и др.] // Вопросы психологии. - 1993. - №2. - С. 35-43.

\section{References}

1. Vitkovskaia, M. I. (2000). Obuchenie mladshikh shkol'nikov v sovmestnoi deiatel'nosti. p. 96. Pskov: PGPI imeni S.M. Kirova

2. Vygotskii, L. S. (1956). Izbrannye psikhologicheskie issledovaniia. p. 479. M.: Pedagogika

3. Glazkova, A., \& Glazkova, A. I. Organizatsiia individual'noi, gruppovoi, kollektivnoi deiatel'nosti. Nachal'naia shkola,1999, 10, pp. 43-49.

4. Liimets, Kh. I., \& Liimetes, Kh. I. (1975). Gruppovaia rabota na uroke. P. 62. M.: Nauka

5. Rodzhers, K. (2002). Svoboda uchit'sia. p. 527. M.: Smysl

6. Romashina, S. Ia., \& Maier, A. A. (2010). Fasilitatsiia razvitiia subekta obrazovaniia: Uchebno-metodicheskoe posobie. p. 63. M.: MGPU

7. Tsukerman, G. A., \& Elizarova, N. A. (1993). Obuchenie uchebnomu sotrudnichestvu. Voprosy psikhologii, 2, pp. 35-43.

Маслова Елена Александровна - канд. пед. наук, учитель начальных классов ГБОУ г. Москвы «Школа №2103», Россия, Москва.

Maslova Elena Aleksandrovna - candidate of pedagogical sciences, elementary school teacher, School №2103, Russia, Moscow. 